\title{
Geographic Disparities in the Relation between English Proficiency and Health Insurance Status among Older Latino and Asian Immigrants
}

\author{
Junghyun Kim ${ }^{1}$, Katy-Lauren Ford ${ }^{2}$, and Giyeon Kim $^{3}$ \\ ${ }^{1}$ Research \& Development, Seoul Welfare Foundation, 21, Baekbeom-ro, 31-gil, Mapo-gu, Seoul, \\ South Korea \\ ${ }^{2}$ Department of Psychology, The University of Alabama, Tuscaloosa, AL, USA \\ ${ }^{3}$ Department of Psychology, Chung-Ang University, Seoul, South Korea
}

\section{Abstract}

This study examines whether English proficiency and geographic context explain health insurance status among older Latino and Asian immigrants in the U.S. Drawn from the 2010-2012 ACS PUMS, 57,936 Latino and 47,742 Asian immigrants aged 65 and older were selected. Logistic regression analysis was conducted for the U.S. as a whole and separately by geographic region. In the entire U.S., having limited English proficiency (LEP) and being proficient in English (EP) increased odds of being uninsured among Latino immigrants, whereas LEP and EP decreased odds of being uninsured among Asian immigrants. In the stratified analyses for geographic regions, there were significant ethnic differences in the directionality of the relation between English proficiency and uninsured status. Regional institutions should take care to expand access to information on health care and insurance coverage to racial/ethnic minorities, taking into account the characteristics of these groups at the local level.

\section{Keywords}

Older immigrants; Health insurance; English proficiency; Geography; Health disparities

\section{Introduction}

Uninsurance is an American epidemic with enormous costs to society, including not only financial costs, but also diminished personal health for the uninsured (Institute of Medicine of the National Academies [IOM], 2009). Uninsured people are more likely to have limited access to health care and receive poor quality of health services (Abreu and Hynes 2009;

Junghyun Kim, jhkim@welfare.seoul.kr.

Author Contribution Junghyun Kim contributed to develop concept, design, acquisition of data, analysis and interpretation of data, and preparation of manuscript. Katy-Lauren Ford interpreted results of statistics and prepared manuscript. Giyeon Kim contributed to design, interpretation of data, and preparation of manuscript.

Compliance with Ethical Standards

Conflict of Interest No disclosures to report.

Publisher's Note Springer Nature remains neutral with regard to jurisdictional claims in published maps and institutional affiliations. 
Derose et al. 2009), and it has been shown that high rates of uninsurance in a community can reduce the quality and accessibility of healthcare services for all residents, regardless of insurance status (IOM 2009). Amongst known correlates of uninsured status, immigrant status clearly stands out. Previous studies have found that immigrants tend to have higher uninsured rates than U.S. born citizens due to the lack of access to coverage-providing employment, economic vulnerability, illegal immigration status, and legislative restrictions (Derose et al. 2007; Gubernskaya et al. 2013; Ku 2009). Especially of note, older immigrants are three times as likely as their U.S. born counterparts to be uninsured and tend to rely on informal caregivers such as adult children and spouses, not public assistance (Choi 2011; Reyes and Hardy 2014).

One important factor in explaining disparities in health insurance coverage among immigrant populations is limited English proficiency (LEP). Recent studies have demonstrated that immigrants with LEP are significantly less likely to have health insurance coverage than their English-proficient counterparts (e.g., Liebert and Ameringer 2013; Bridges et al. 2012; Choi 2011; Kim et al. 2011; Reyes and Hardy 2014; Valenzuela 2012). It has been shown that immigrants and those with LEP encounter more difficulty obtaining appropriate information about the eligibility criteria and application process (Abreu and Hynes 2009); and older age, LEP, and immigrant status are all risk factors for low health literacy (Kutner et al. 2006). Another significant contributor to uninsured status is geographic context (Holahan 2011; Johnson et al. 2010). For example, residential location characteristics (e.g., the prevalence of immigrants in the population, state health care policies, etc.) have been identified as significant predictors of health insurance coverage among immigrants (Derose et al. 2007). Furthermore, the cost of health insurance coverage since the implementation of the Affordable Care Act has been shown to vary by geographic location (Wu n.d.). The notion of geographic context as a predictor of variation in uninsurance rates is useful because it allows for identification of areas where local or state policies are working to improve coverage rates for a particular population.

Low rates of health insurance among disadvantaged populations including immigrants have been well documented (e.g., Fairlie and London 2009; López-Cevallos 2014; Pandey and Kagotho 2010; Parmet and Fischer 2013; Witkin 1999; Ye et al. 2012), and health insurance coverage is considered as a mediator between ethnicity and health care access (Alegria et al. 2012; USDHHS 2000). For older immigrants, immigration status is an important factor affecting health insurance status (Angel et al. 2002; Carrasquillo et al. 2000; Choi 2006; Choi 2011; Ku 2009). However, there are relatively few studies that specifically examine the other factors contributing to this phenomenon among older immigrants. Given the limited knowledge on this topic, this study focused on the uninsured older Latino and Asian immigrants, the two biggest ethnic immigrant groups in the U.S., specifically examining whether English proficiency and geographic context help to explain their health insurance status. In order to address the uninsurance epidemic (IOM 2009), the correlates of uninsurance must be identified. Thus, the purpose of this study is to explores how health insurance status might differ in terms of English proficiency by geographic region among older Latino and Asian immigrants in the U.S. Specific hypotheses of this study are the following: (1) both Latino and Asian LEP or English proficient (EP) older immigrants will 
be more likely to be uninsured than those speaking English only (EO) and (2) the uninsured status by English proficiency will be different by geography and ethnicity.

\section{Methods}

\section{Sample}

Data were drawn from the American Community Survey Public Use Microdata Sample (ACS PUMS) which offers recent demographic and economic indicators. (Conway and Rork 2010; Hough and Swanson 2006). The Bureau of the Census offers a representative secondary dataset in the United States through the PUMS to enable census data users to make their own estimates (Conway and Rork 2010; Griffin and Waite 2006). This study analyzed the publicly available 2010-2012 ACS 3-year PUMS data file which was the latest version of multiyear ACS datasets based on $3 \%$ of the whole population in the U.S. Given our focus on older Latino and Asian immigrants in the present study, we selected respondents who were aged 65 and older Latino/Asian including combination with other races and born outside the U.S. (either Latin America [identified as Latino immigrants] or Asia [identified as Asian immigrants]).

There were two main variables of interest in the present study: English proficiency and geography. Because we hypothesized that the ability to speak other languages would be associated with health insurance status, the selected older immigrants were divided into three groups according to English speaking ability: those who spoke English not well or not at all (LEP group; $n=29,982$ Latinos and $n=19,941$ Asians); those who spoke English well or very well (EP group; $n=17,967$ Latinos and $n=24,039$ Asians); and those who spoke only English (EO group; $n=9987$ Latinos and $n=3762$ Asians). In order to assess the role of geographic region in the relation between English proficiency and uninsured status, the selected sample was divided into four geographic regions: Northeast ( $n=11,145$ Latinos and $n=8952$ Asians); Midwest ( $n=2418$ Latinos and $n=4026$ Asians); South $(n=25,191$ Latinos and $n=9045$ Asians); and West ( $n=19,182$ Latinos and $n=25,719$ Asians).

\section{Measures}

Health Insurance-Health insurance status was measured by a single item: "is this person currently covered by any of the following types of health insurance or health coverage plans?" Participants responded "Yes" or "No" for each type of coverage in items such as (1) insurance through a current or former employer or union (of this person or another family member), (2) insurance purchased directly from an insurance company (by this person or another member), (3) Medicare, for people 65 and older, or people with certain disabilities, (4) Medicaid, Medical Assistance, or any kind of government-assistance plan for those with low income or a disability, (5) TRICARE or other military health care, (6) VA (including whose who have ever used or enrolled for VA health care), (7) Indian Health Service, (8) any other type of health insurance or health coverage plan. This study used a dichotomized classification of having health insurance coverage (coded as 0 ) or no health insurance coverage (coded as 1). 
English Proficiency-In order to identify immigrants by English proficiency, using information on languages spoken at home, we identified immigrants who reported English as the only language spoken at home as those who spoke only English (EO). Second, for those who spoke a language other than English at home, we used English proficiency assessed by using a "How well does this person speak English?" Responses were reported on a four point Likert-type scale ("very well," "well," "not well," and "not at all"). Those who described their English-speaking ability as "very well" or "well" but spoke another language at home were regarded to be proficient in English (EP) and those who described their English-speaking ability as "not well" or "not at all" were regarded to have limited English proficiency (LEP).

Region-The ACS PUMS offers region, division, state, and Public Use Microdata Areas (PUMAs, the most detailed geographic areas available). Of the geographic identifiers, this study classified individuals living in four main regions of the United States (Midwest, Northeast, South, and West), as defined by the ACS PUMS.

Covariates-Socio-demographic variables included as covariates were age, sex, marital status (married or single), education attainment (<high school education, high school graduation, or some college or more), annual household income ( $<\$ 11,600, \$ 11,600$ $\$ 36,900, \$ 37,000-\$ 79,900$, or $>\$ 80000$ ), decade of arrival in the U.S. (before 1960,1960 1979, 1980-1999, 2000 and later), and naturalized U.S. citizen status (U.S. citizen by naturalization or not a citizen of the U.S.).

\section{Data Analysis}

For the purpose of descriptive statistics, percentages or means and standard deviations of each variable were reported in each group. Chi-square or analysis of variance (ANOVA) tests were used to evaluate group differences. Finally, logistic regression analyses of uninsured rates were conducted for all U.S. and by geographic region after adjusting for covariates. All analyses were weighted with a centered person-level weight based on the person weight provided in the US Census PUMS files. All analyses were conducted using the SPSS software version 17.0.

\section{Results}

\section{Background Characteristics}

As shown in Table 1 there were significant differences in all background characteristics across three language groups in both Latino and Asian immigrants. Regarding the distribution of geographic region, about $43 \%$ of Latinos with LEP and EP lived in the South, whereas $43 \%$ of Latinos with EO lived in the Northeast. About half of Asians lived in the West regardless of their English proficiency. Both Latinos and Asians with LEP were significantly older than those with EP. More than half of each ethnic group was female. Over half of Latinos and Asians with LEP and EO were single, with Asians being more likely to be married. Differences in educational attainment were substantial; Latinos and Asians with LEP had lower levels of educational attainment than EP and EO groups. Household income was also statistically significant across the three language groups within each ethnic group. 
Latino and Asian immigrants with LEP had lower rates of naturalized citizenship than EP and EO groups. Many EP or EO immigrants moved to the U.S. earlier than did LEP immigrants. In both Latinos and Asians, uninsured rates were significantly higher among LEP immigrants than EP or EO immigrants.

\section{Uninsured Rates by Region and English Proficiency}

Table 2 summarizes regional differences in uninsured rates by English proficiency. In the entire U.S., uninsured rates were significantly higher in the LEP group than the EP or EO groups for both Latinos and Asians. For Latino immigrants, LEP individuals living in the Midwest had the highest uninsured rates (20.2\%) followed by LEP individuals living in the South (13.9\%), West (10.5\%), and Northeast (7.9\%). For Asian immigrants, the highest uninsured rates were found among LEP individuals living in the South (18.2\%) followed by LEP individuals in the Midwest (13.5\%) and Northeast (10.0\%).

\section{The Effect of English Proficiency on Uninsured Status in the U.S. and by Region}

As shown in Table 3, main effects of region and English proficiency were significant among Latino immigrants in the entire U.S., after adjusting for covariates (see the first column). In the entire U.S., Latino immigrants living in the Midwest $(\mathrm{OR}=1.69,95 \% \mathrm{CI}=1.65-1.73)$ and South $(\mathrm{OR}=1.41,95 \% \mathrm{CI}=1.39-1.43)$ were more likely to be uninsured, whereas those living in the Northeast $(\mathrm{OR}=0.72,95 \% \mathrm{CI}=0.70-0.73)$ were less likely to be uninsured than those living in the West. Compared to EO Latino immigrants, those with LEP $(\mathrm{OR}=1.44,95 \% \mathrm{CI}=1.41-1.47)$ and $\mathrm{EP}(\mathrm{OR}=1.07,95 \% \mathrm{CI}=1.05-1.10)$ were significantly more likely to be uninsured. When the effect of English proficiency was examined within each region, Latino immigrants with LEP and EP in the Northeast, Midwest, and South were significantly more likely to be uninsured than the EO group, whereas the opposite pattern was found in the West. In the West, Latino immigrants with LEP and EP were less likely than EO individuals to be uninsured.

Table 4 shows that the main effects of region and English proficiency were also significant among Asian immigrants. Unlike Latino immigrants, Asian immigrants with LEP (OR = $0.91,95 \% \mathrm{CI}=0.87-0.95)$ or $\mathrm{EP}(\mathrm{OR}=0.66,95 \% \mathrm{CI}=0.63-0.69)$ were less likely to be uninsured than those with EO in the entire U.S., after adjusting for covariates (see the first column in the Table 4). In the entire U.S., Asian immigrants living in the Northeast (OR = $1.72,95 \% \mathrm{CI}=1.68-1.76)$, Midwest $(\mathrm{OR}=2.32,95 \% \mathrm{CI}=2.26-2.38)$ and South $(\mathrm{OR}=$ $3.22,95 \% \mathrm{CI}=3.15-3.28$ ) were more likely to be uninsured than those living in the West. When the effect of English proficiency was examined within each region, Asian immigrants with LEP and EP in the Northeast and West were significantly less likely to be uninsured than the EO group. In the South, Asian immigrants with LEP were significantly more likely to be uninsured than the EO group whereas the opposite pattern was found in the EP group.

\section{Discussion}

This study found evidence that uninsured status differs by English proficiency across regions between older Latino and Asian immigrants in the United States. Overall, we observed opposite patterns of the effect of English proficiency on uninsured status between Latinos 
and Asians: while LEP and EP were associated with higher uninsured rates among Latino immigrants, LEP and EP were associated with lower uninsured rates among Asian immigrants. It is of particular interest that these distinct ethnic patterns were influenced greatly by geographic region. For Latino immigrants, those in the Midwest and South were more likely to be uninsured than those in the West and those in the Northeast were less likely to be uninsured than those in the West. Asian immigrants in the Northeast, Midwest, and South were more likely to be uninsured than those in the West. LEP was a significant contributor (either positively or negatively) to uninsured status among older immigrants regardless of ethnicity and geographic region. As we expected in our first hypothesis, Latino immigrants with LEP or EP were more likely to be uninsured than those with EO. However, this was not the case for Asian immigrants: those with LEP or EP were less likely to be uninsured than their EO counterparts. These findings suggest the importance of considering ethnicity, English proficiency and geographic location together as important contributing factors to disparities in health insurance status among older immigrants in the U.S.

The most intriguing finding was regional variations in uninsured status by English proficiency within each ethnic group. For the Asian group, LEP/EP immigrants in the Northeast and West were less likely to be uninsured than those with EO in contrast to LEP/EP immigrants in the South. Considering the fact that three of four Asian immigrants reside in the West and Northeast and their uninsured rates were lower than those in the South or Midwest in the present study (see Table 1), these findings reflect the ethnic density effect. The effect presents older immigrants living in a co-ethnic community with well-developed safety nets, culturally competent service providers, and immigrant advocacy are likely to have better health than those without co-ethnic groups (Choi 2009; Derose et al. 2007). Possibly, older immigrants with LEP in these regions have better access to information about health insurance through individual social ties (Choi 2009). Based on these speculations, older Asian immigrants in less established destinations such as the South or Midwest might have relatively weak co-ethnic community and their English proficiency might be a main contributor to accessing the health insurance system.

Conversely, considering our results indicating that LEP was a barrier to uninsured status among Latino immigrants even in the South where almost half of the Latino immigrants reside, the ethnic density effect in uninsured status among Latino immigrants might be weaker than it is among Asian immigrants. The relatively low level of education and income among Latinos in the South (see Table 1) may account for some of this discrepancy. However, the West with the second largest number of Latino immigrants showed associations between English proficiency and uninsured status similar to that seen among Asian immigrants in our study. From these results, we speculate regional variations in the ethnic density effect on accessing health insurance within the Latino group. Future research should consider cultural differences in uninsured status in each ethnic group for offering implications to reduce health disparities and respect diversity among older immigrants.

It should be highlighted that the West showed the same patterns of the effect of English proficiency on uninsured status among Latino and Asian immigrants. As shown in Table 2, the rate of uninsured status was relatively lower than the other regions regardless of ethnicity. Also, in both ethnic groups, LEP or EP decreased odds of being uninsured 
compared EO. We could speculate that most of the Latino and Asian immigrants residing in the West benefit from health insurance as there may be more resources to immigrants such as culturally well-established health service systems including culturally capable service providers supporting for even uninsured immigrants in the region based on the ethnic density effect. For example, regardless of immigration status, Medi-Cal, the Medicaid program in California, benefits cover emergency and health programs for low-income immigrants vary by county in California. Google shows there are hundreds of ethnic medical centers giving geriatric treatments in Los Angeles County. In addition, the county of Los Angeles Department of Public Health runs multi-lingual appointment and referral hotline for supporting both legal and illegal immigrants with LEP(LAcounty.gov). Thus, older immigrants in the county may access easier health insurance system and health services than them residing in the other regions.

In the wake of the sweeping reforms enacted by the Patient Protection and Affordable Care Act (ACA 2010), it remains important to evaluate the policies' success. Many ACA-related changes affecting Medicare beneficiaries (for adults 65+, as in our sample) are only applicable to those qualifying for and enrolled in the program. Illegal or undocumented immigrants do not qualify for Medicare coverage, and although we do not have information regarding respondents' immigration status (legal, undocumented, etc.) in the present study, we did find that older adults without citizenship were consistently more likely to be uninsured regardless of ethnicity and region. It is possible that some of these non-citizens would not qualify for health care coverage, even under the ACA. Legislation and enforcement of anti-immigrant law could aggravate the current situation. Immigrants excluded from health care system would lose opportunities to benefit from a wider range of health care services and their right to receive health care services would be deprived because of anti-immigration policy. The policy could also negatively impact the perceptions and behaviors of health providers' as they deal with the health care needs of immigrants (Martinez et al. 2015). For both older and younger undocumented immigrants, being uninsured is not optional; thus, policies aimed at expanding coverage to more immigrants of all ages could help to improve the burden placed on the health care system by these uninsured users.

Nevertheless, a portion of the sample may have qualified for Medicare coverage but were not enrolled. The present findings point to geographical region, constituents' Englishlanguage ability, and socioeconomic factors as contributors to uninsurance among Latino and Asian immigrant older adults. The unique interactions of LEP and geographic region identified by this study have several implications for policy makers and health advocates for older adults. The observation that the patterns of LEP's influence on uninsurance rates varied by geographic region suggest that states' cooperation in improving health care access will be essential. Blanket federal policies may be ineffective at the community level. State level officials can be more familiar with the unique characteristics of their communities, and can thus better advocate for the needs of their residents. It will behoove states to take active roles in the shaping of health care reforms within their borders, rather than passively dissenting with the federal policies. 
The main finding of the present study is that English proficiency was a meaningful factor influencing on uninsured status among older immigrants and its direction of influence depends on ethnicity and region. This finding highlights the need for culturally competent, linguistically appropriate health insurance materials and providers. In order to decrease uninsured rates among older immigrants, applications for Medicare or other coverage programs should be easily accessible to those with LEP and/or low health literacy. Special attention should be paid to the ethnic density of a given community, as well as to the socioeconomic characteristics of local ethnic groups. This can help to identify the best means for public service announcements regarding health insurance information.

Some study limitations should be noted. First, this study used a simple geographic identifier based on ACS PUMS region. Dividing the United States into four regions is too gross to consider the differences between well-established residences and new destinations for immigrants. Future investigation focusing on lower levels of geography such as state or county will offer more directions for future policy to improve health insurance coverage among older immigrants who reside in specific geographic location and do not speak English very well. Stigma or marginalization in health care or service use should also be discussed at the local level. Second, this exploratory study analyzed only bivariate health insurance status (uninsured or insured). Future studies might benefit from analyzing various types of health insurance coverage and respondents' health status. Third, this study does not consider heterogeneity within Latino and Asian immigrants. Self-reported measures might also have the limitation of over/under estimating English proficiency. Other important cultural or social factors such as social safety nets, social ties, or culturally competent service providers in co-ethnic community might have contributed to more affluent interpretation.

In conclusion, this study provides clear evidence of regional variation of the role of English proficiency in uninsured rates among older Latino and Asian immigrants in the United States. English proficiency and geographic location were important contributing factors to disparities in health insurance among older immigrants in the U.S. These findings provide visions to improve the access to health care through increasing health insurance coverage among older immigrants with LEP in the U.S., as well as to reduce regional disparities in uninsured status among older immigrants. In order to reduce inequitable health insurance benefits to older immigrants, health care professionals should be more culturally, linguistically, and geographically sensitive, especially for culturally and geographically isolated older immigrants. Policy makers need to be aware of differential benefits of expanding health insurance coverage for older immigrants by English proficiency and region. Explaining specific contributors to uninsured status by English proficiency in lower levels of region may be a reasonable next step for research, which may help reduce ethnic disparities in health insurance coverage and ultimately improve the quality of health care among older immigrants.

\section{Acknowledgments}

Funding This study was funded by the National Institute on Aging (K01AG045342). 


\section{References}

Abreu M, \& Hynes HP (2009). The Latino health insurance program : A pilot intervention for enrolling Latino families in health insurance programs. Preventing Chronic Disease: Pulibc Health Research, Practice, and Policy, 6(4), 1-9.

Alegria M, Lin J, Chen C-N, Duan N, Cook B, \& Meng X-L (2012). The impact of insurance coverage in diminishing racial and ethnic disparities in behavioral health services. Health Services Research, 47(3 Pt 2), 1322-1344. 10.1111/j.1475-6773.2012.01403.x. [PubMed: 22568675]

Angel RJ, Angel JL, \& Markides KS (2002). Stability and change in health insurance among older Mexican Americans: Longitudinal evidence from the Hispanic Estabilished populations for epidemiologic study of the elderly. American Journal of Public Health, 92, 1264-1271. [PubMed: 12144982]

Bridges AJ, Andrews AR, \& Deen TL (2012). Mental health needs and service utilization by Hispanic immigrants residing in mid-southern United States. Journal of Transcultural Nursing : Official Journal of the Transcultural Nursing Society / Transcultural Nursing Society, 23(4), 359-368. $10.1177 / 1043659612451259$.

Carrasquillo O, Carrasquillo AI, \& Shea S (2000). Health insurance coverage of immigrants living in the United States: Differences by citizenship status and country of origin. American Journal of Public Health, 90(6), 917-923. [PubMed: 10846509]

Choi S (2006). Insurance status and health service utilization among newly-arrived older immigrants. Journal of Immigrant and Minority Health, 8(2), 149-161. 10.1007/s10903-006-8523-3. [PubMed: 16649130]

Choi JY (2009). Contextual effects on health care access among immigrants: Lessons from three ethnic communities in Hawaii. Social Science \& Medicine (1982), 69(8), 1261-1271. 10.1016/ j.socscimed.2009.08.001. [PubMed: 19720437]

Choi S (2011). Longitudinal changes in access to health care by immigrant status among older adults: The importance of health insurance as a mediator. The Gerontologist, 51(2), 156-169. 10.1093/ geront/gnq064. [PubMed: 20693237]

Conway KS, \& Rork JC (2010). "Going with the flow"-A comparison of interstate elderly migration during 1970-2000 using the (I) PUMS versus full census data. The Journals of Gerontology Series B: Psychological Sciences and Social Sciences, 65(6), 767-771. [PubMed: 20139134]

Derose KP, Escarce JJ, \& Lurie N (2007). Immigrants and health care: Sources of vulnerability. Health Affairs (Project Hope), 26(5), 1258-1268. 10.1377/hlthaff.26.5.1258. [PubMed: 17848435]

Derose KP, Bahney BW, Lurie N, \& Escarce JJ (2009). Review: Immigrants and health care access, quality. and cost. Medical care research and review : MCRR, 66, 355-408. 10.1177/1077558708330425. [PubMed: 19179539]

Fairlie RW, \& London R. a. (2009). Who is at risk of losing and gaining health insurance? Industrial Relations: A Journal of Economy and Society, 48(2), 287-310. 10.1111/j.1468-232X. 2009.00558.x.

Griffin DH, \& Waite PJ (2006). American community survey overview and the role of external evaluations. Population Research and Policy Review, 25(3), 201-223.

Gubernskaya Z, Bean FD, \& Van Hook J (2013). Why does naturalization matter for the health of older immigrants in the United States? Journal of Health and Social Behavior, 54(4), 426.

Holahan J (2011). The 2007-09 recession and health insurance coverage. Health Affairs (Project Hope), 30(1), 145-152. 10.1377/hlthaff.2010.1003. [PubMed: 21134911]

Hough GC, \& Swanson DA (2006). An evaluation of the American community survey: Results from the Oregon test site. Population Research and Policy Review, 25(3), 257-273.

Institute of Medicine of the National Academies. Board on Health Care Services. (2009). America's uninsured crisis: Consequences for health and health care Washington, D.C: National Academies Press.

Johnson PJ, Blewett L. a., \& Davern M (2010). Disparities in public use data availability for race, ethnic, and immigrant groups: National surveys for healthcare disparities research. Medical Care, 48(12), 1122-1127. 10.1097/MLR.0b013e3181ef984e. [PubMed: 20966785] 
Kim G, Worley CB, Allen RS, Vinson L, Crowther MR, Parmelee P, \& Chiriboga D. a. (2011). Vulnerability of older Latino and Asian immigrants with limited English proficiency. Journal of the American Geriatrics Society, 59(7), 1246-1252. 10.1111/j.1532-5415.2011.03483.x. [PubMed: 21718269]

$\mathrm{Ku} \mathrm{L}$ (2009). Health insurance coverage and medical expenditures of immigrants and native-born citizens in the United States. American Journal of Public Health, 99(7), 1322-1328. 10.2105/ AJPH.2008.144733. [PubMed: 19443829]

Kutner M, Greenburg E, Jin Y, \& Paulsen C (2006). The Health Literacy of America's Adults: Results from the 2003 National Assessment of Adult Literacy. NCES 2006-483. National Center for Education Statistics

Liebert S, \& Ameringer CF (2013). The Health care safety net and the aff ordable care act: implications for hispanic immigrants. Public Administration Review, 73(6), 810-820. 10.1111/ puar.12147.810.

López-Cevallos D (2014). Are Latino immigrants a burden to safety net services in nontraditional immigrant states? Lessons from Oregon. American Journal of Public Health, 104(5), 781-786. 10.2105/AJPH.2013.301862. [PubMed: 24625168]

Martinez O, Wu E, Sandfort T, Dodge B, Carballo-Dieguez A, Pinto R, Rhodes S, Moya E, \& ChavezBaray $S$ (2015). Evaluating the impact of immigration policies on health status among undocumented immigrants: A systematic review. Journal of Immigrant Minority Health, 17, 947970. 10.1007/s10903-9968-4. [PubMed: 24375382]

Pandey S, \& Kagotho N (2010). Health insurance disparities among immigrants: Are some legal immigrants more vulnerable than others? Health \& Social Work, 35(4), 267-279. 10.1093/hsw/ 35.4.267. [PubMed: 21171534]

Parmet W, \& Fischer S (2013). Human rights and immigrants' access to care. Salud Pública de México, 55(6), 631-637 Retrieved from http://www.ncbi.nlm.nih.gov/pubmed/24715016. [PubMed: 24715016]

Patient Protection and Affordable Care Act (ACA) (2010) 42 U.S.C.§ 18001 et seq.

Reyes AM, \& Hardy M (2014). Another health insurance gap: Gaining and losing coverage among natives and immigrants at older ages. Social Science Research, 43C, 145-156. 10.1016/ j.ssresearch.2013.10.001.

US Department of Health and Human Services, \& Office of Disease Prevention and Health Promotion. (2000). Healthy people 2010: Understanding and improving health and objectives for improving health Washington, DC: US Department of Health and Human Services.

Valenzuela A (2012). Affordable health care coverage for Mexican immigrants in the Southwest: Stateinitiated reform in the private and public sectors. Arizona State Law Journal, Winter(c), 1-32.

Witkin SL (1999). Interview: Gerontological social work and the UN international year of older persons. Social Work, 44(6), 513-519. [PubMed: 10568024]

$\mathrm{Wu} \mathrm{J}$ (n.d.). Geographical variations in health insurance pricing and coverage Retrieved from 1029 , 2015, from http://www.valuepenguin.com/2015/04/what-geographical-variations-health-insurancepricing-and-coverage-look

Ye J, Mack D, Fry-Johnson Y, \& Parker K (2012). Health care access and utilization among US-born and foreign-born Asian Americans. Journal of Immigrant and Minority Health / Center for Minority Public Health, 14(5), 731-737. 10.1007/s10903-011-9543-9. 


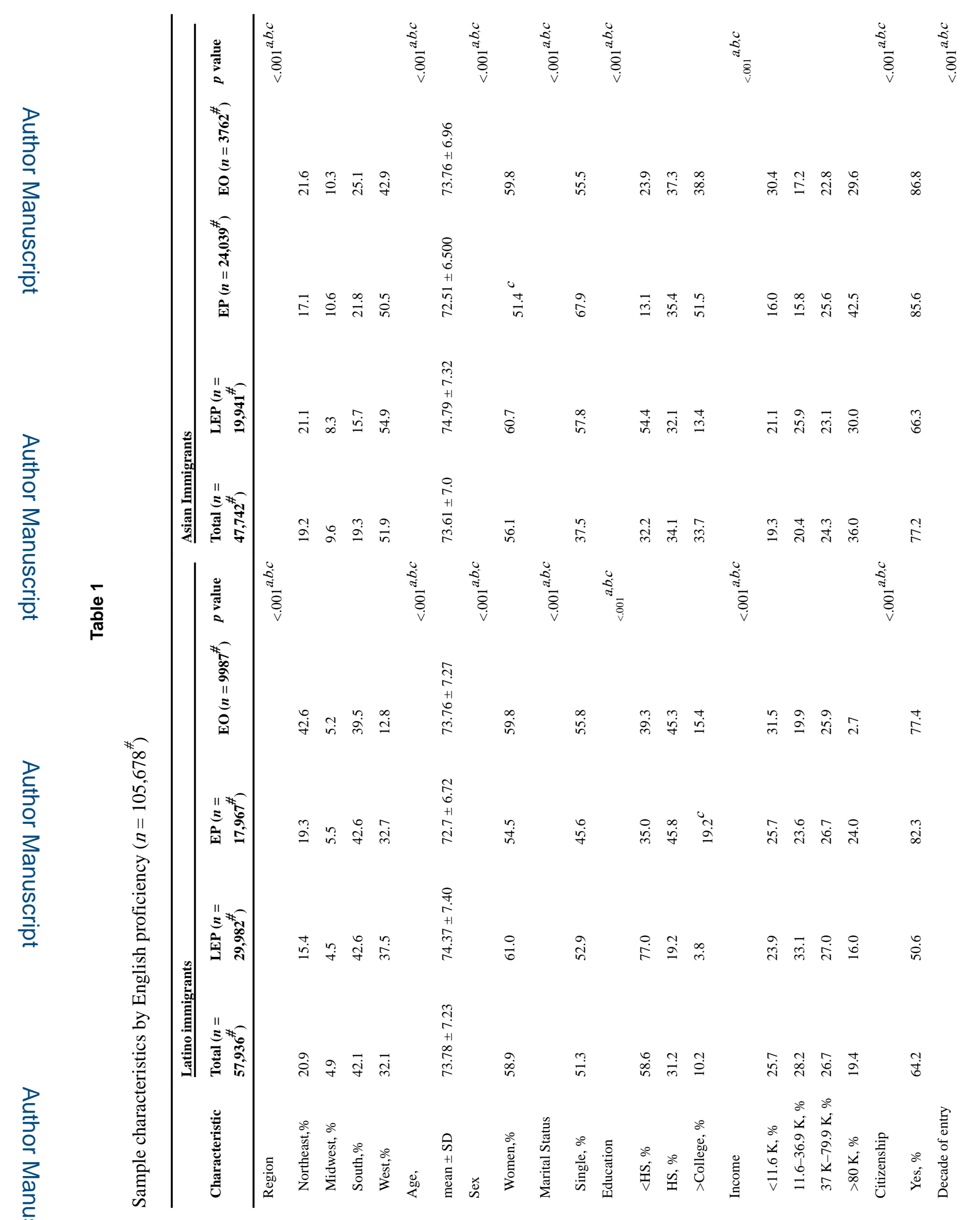


Kim et al.

Page 12

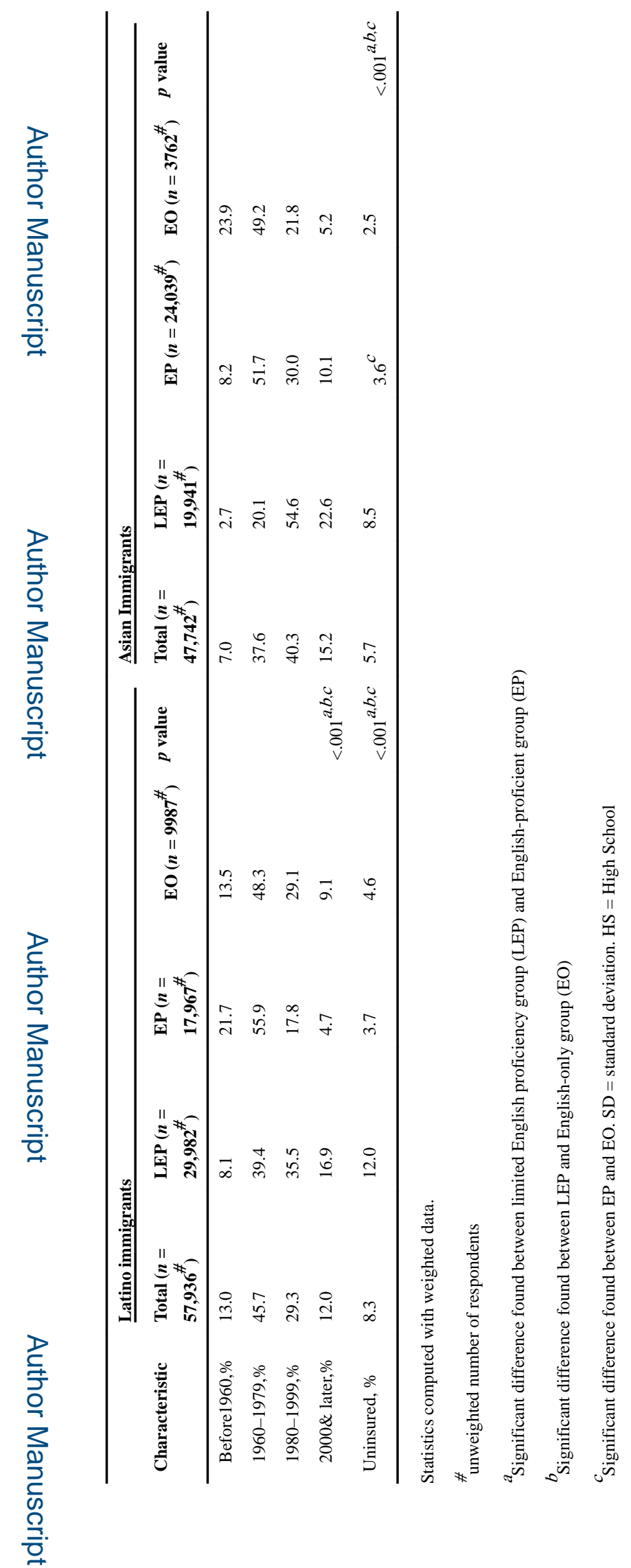

J Cross Cult Gerontol. Author manuscript; available in PMC 2019 April 13. 
Table 2

Uninsured rates of Latino and Asian immigrants by English proficiency and geographic region Uninsured rates

\begin{tabular}{lccccccccc}
\hline \multicolumn{1}{c}{ Uninsured rates } \\
\cline { 2 - 8 } & \multicolumn{1}{l}{ Latino immigrants $\left(\mathbf{n}=\mathbf{5 7 , 9 3 6 ^ { \# } )}\right.$} & \multicolumn{7}{c}{ Asian immigrants $\left(\mathbf{n}=\mathbf{4 7 , 7 4 2}^{\#}\right)$} \\
\hline Region & LEP & EP & EO & $p$ value & LEP & EP & EO & $p$ value \\
All US & 12.0 & 3.7 & 4.6 & $<.001^{a, b, c}$ & 8.5 & 3.6 & 2.5 & $<.001^{a, b, c}$ \\
Northeast & 7.9 & 3.1 & 3.2 & $<.001^{a, b, c}$ & 10.0 & 3.6 & 3.9 & $<.001^{a, b, c}$ \\
Midwest & 20.2 & 3.1 & 4.8 & $<.001^{a, b, c}$ & 13.5 & 5.4 & 0.0 & $<.001^{a, b, c}$ \\
South & 13.9 & 4.2 & 5.8 & $<.001^{a, b, c}$ & 18.2 & 3.6 & 2.8 & $<.001^{a, b, c}$ \\
West & 10.5 & 3.3 & 5.6 & $<.001^{a, b, c}$ & 4.4 & 2.8 & 2.2 & $<.001^{a, b, c}$ \\
\hline
\end{tabular}

statistics computed with weighted data

\# unweighted number of respondents

${ }^{a}$ Significant mean difference found at the 0.05 level between limited English proficiency group (LEP) and English-proficient group (EO)

${ }^{b}$ Significant mean difference found at the 0.05 level between LEP and English-only group (EP)

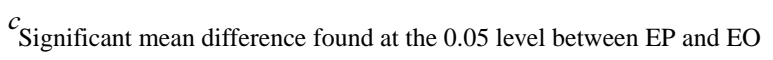




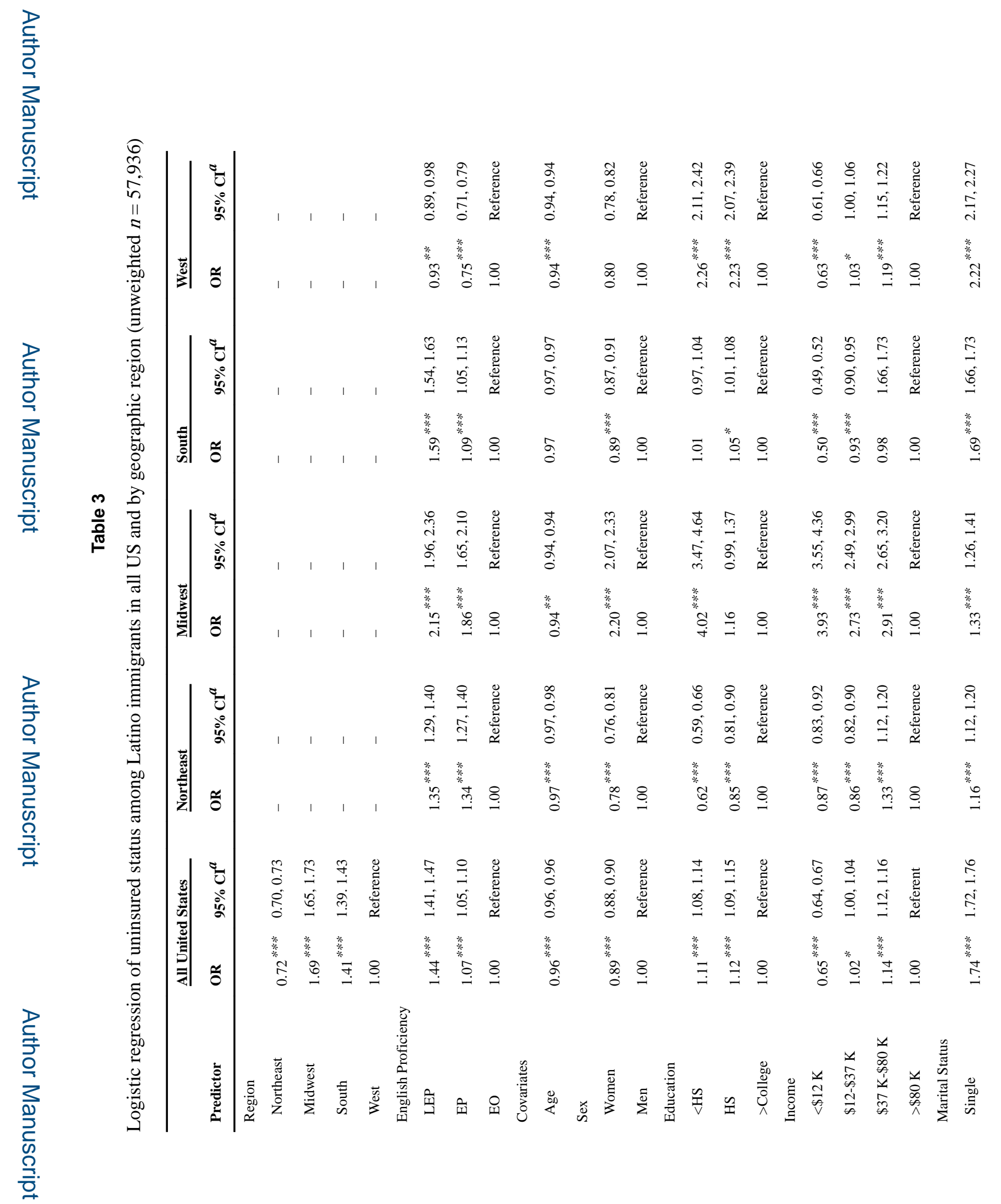

J Cross Cult Gerontol. Author manuscript; available in PMC 2019 April 13. 
Kim et al.

Page 15

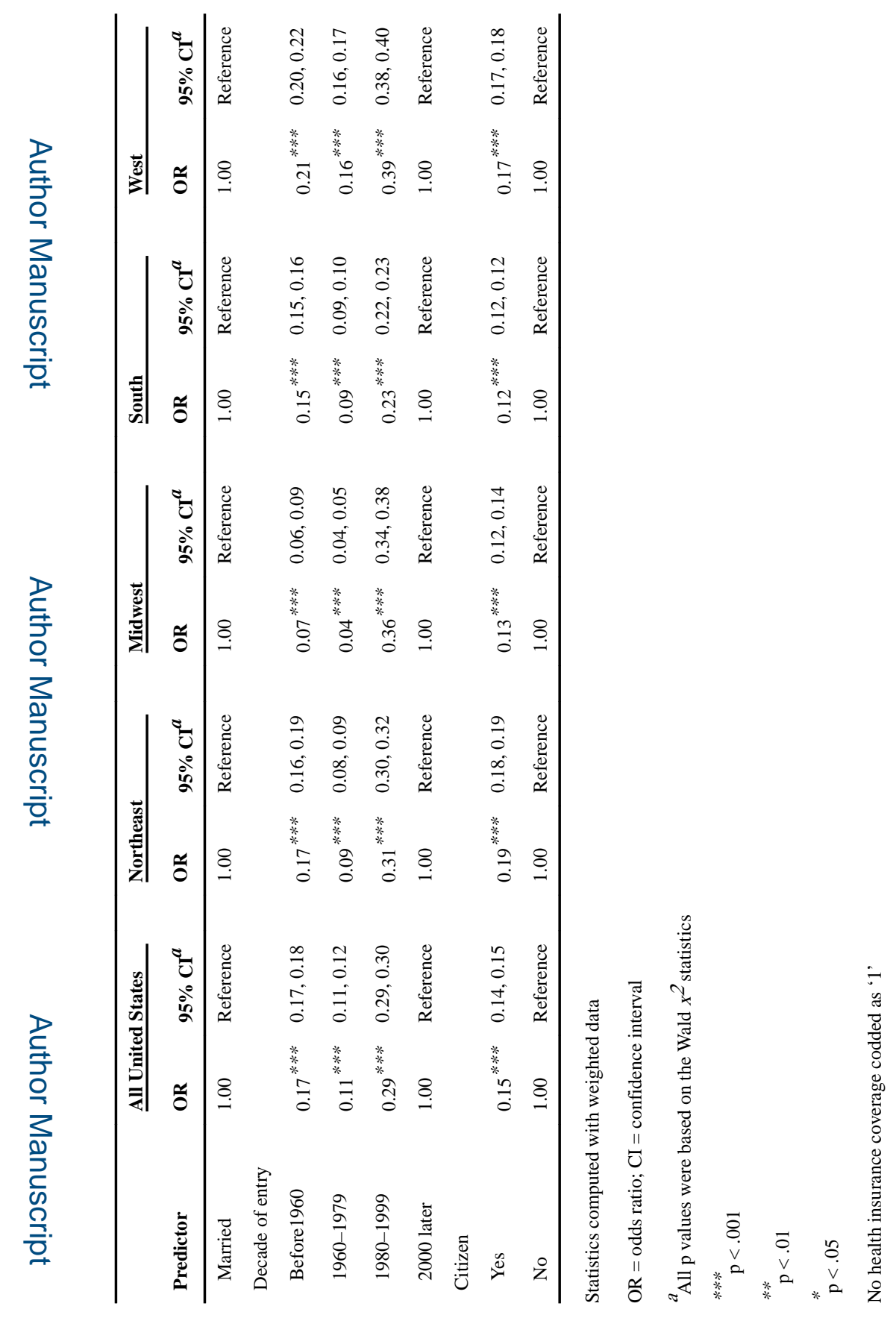

로을

J Cross Cult Gerontol. Author manuscript; available in PMC 2019 April 13. 


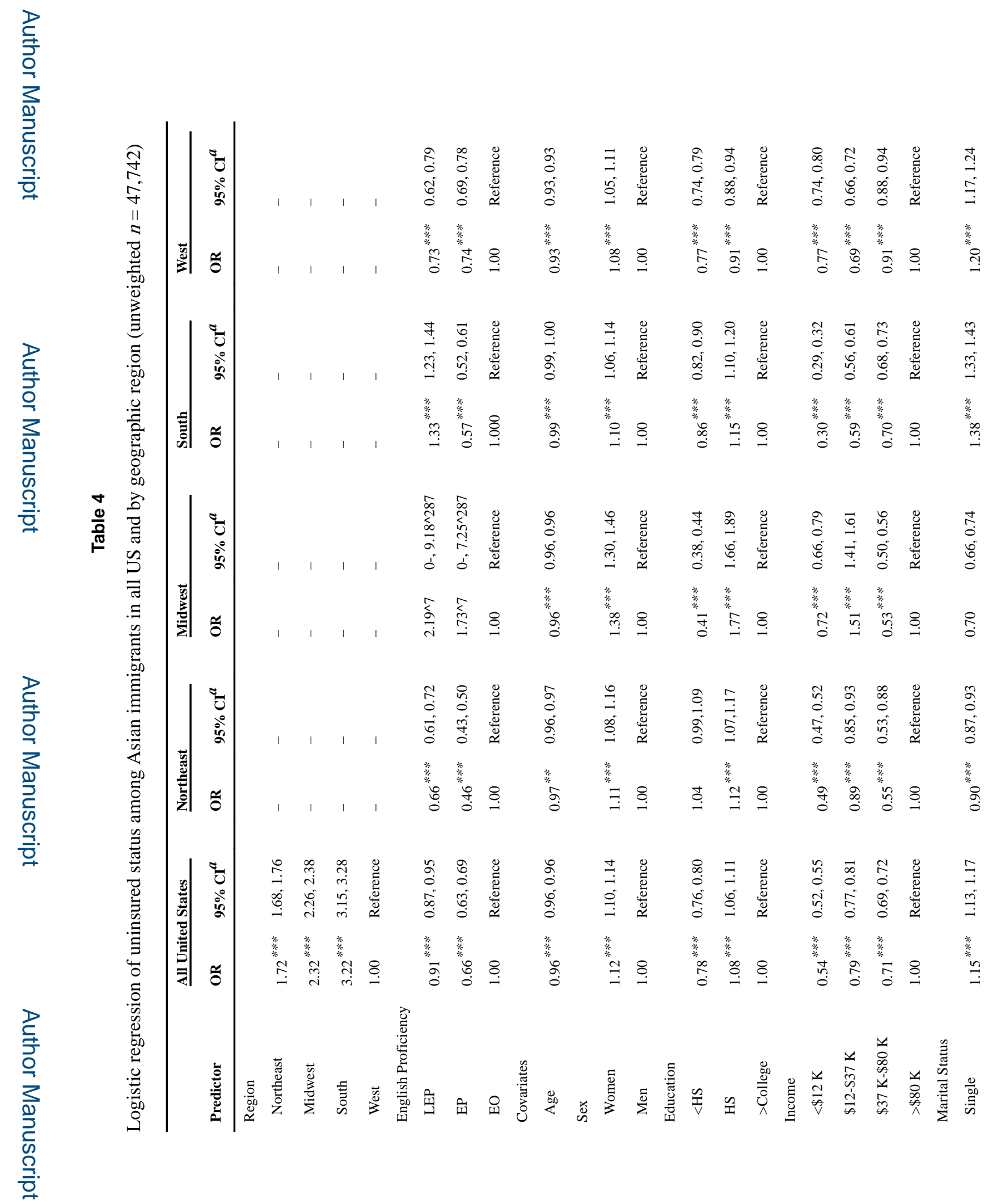

J Cross Cult Gerontol. Author manuscript; available in PMC 2019 April 13. 


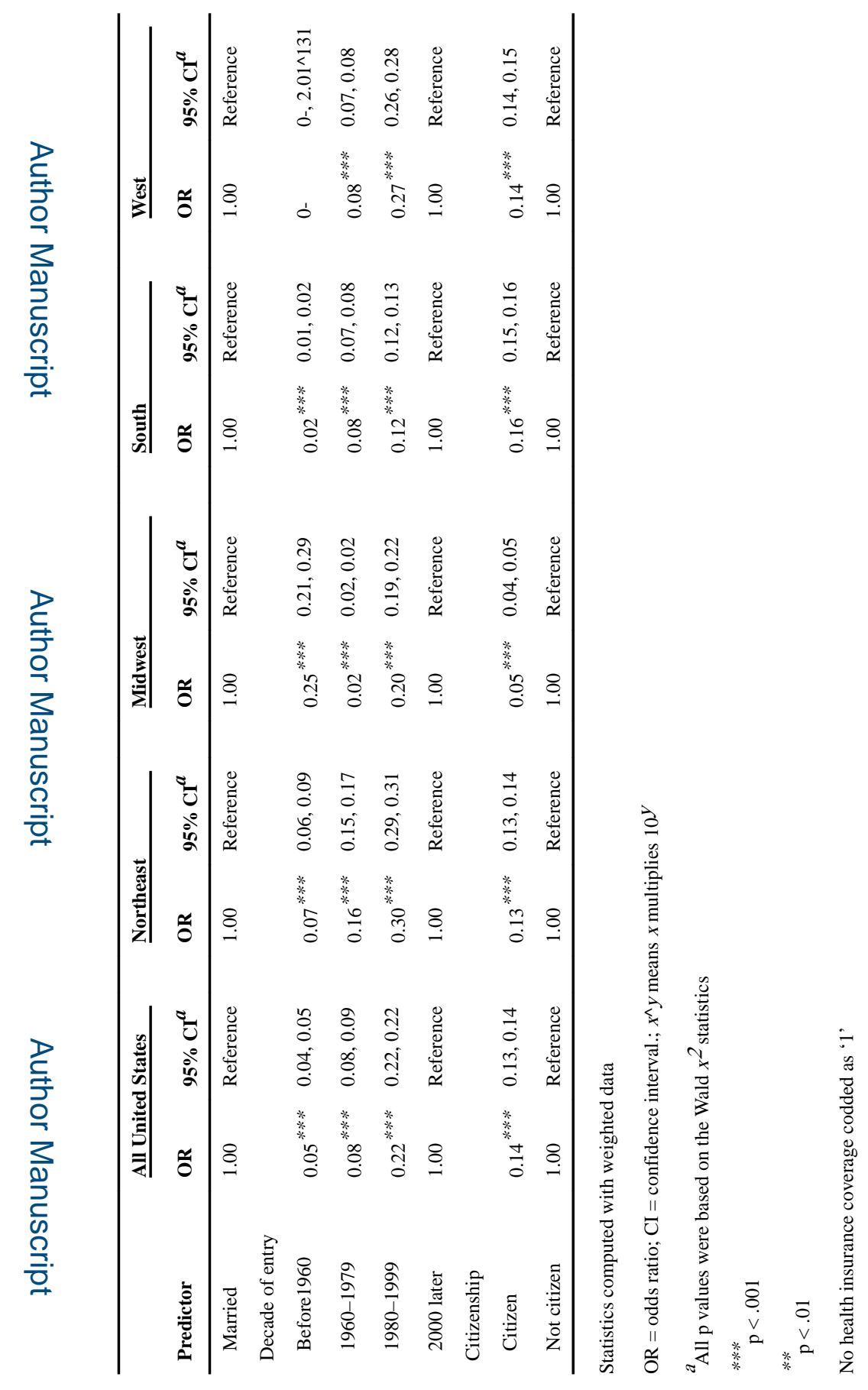

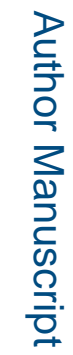

